\title{
Conditions of The Electric Power Line Operation in the Afforestation Regions
}

\author{
YV Zhillkina ${ }^{1 *}$ and Vodennikov DA $^{1}$ \\ ${ }^{1}$ Federal Grid Company of Unified Energy System, Russia
}

ISSN: 2578-0255

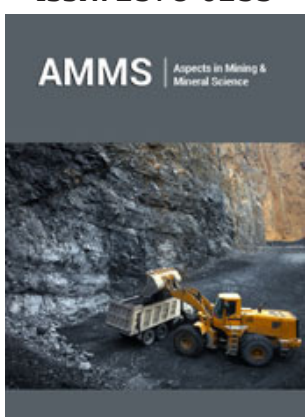

For HTML Version scan this QR code: Federal Grid Company of Unified Energy System, Russia

Submission: 眥 February 14, 2019

Published: : March 11, 2019

Volume 2 - Issue 4

How to cite this article: YV Zhilkina, Vodennikov D. Conditions of The Electric Power Line Operation in the Afforestation Regions. Aspects Min Miner Sci.2(4). AMMS.000599.2019.

DOI: 10.31031/AMMA.2019.02.000546.

Copyright@ YV Zhilkina, This article is distributed under the terms of the Creative Commons Attribution 4.0 International License, which permits unrestricted use and redistribution provided that the original author and source are credited.

\begin{abstract}
Summary
The article views the impact of natural factors (snow, icing, trees falling on the wires, etc.) on the safety of overhead electric power line. The authors suggest technological clearance plan for electric power line. Power lines (transmission lines), as well as wired communication lines in some areas pass through forest plantations (this can be a forest, forest Park areas, forest belts along roads, etc.). Clearing of overhead lines is an integral part of the annual repair program and successful preparation of the electric grid economy for the next autumn-winter period. All work is carried out either with the use of small-scale mechanization, or with the help of mulcher complexes.
\end{abstract}

Keywords: Electric power line operation; Protected zones of overhead lines; Reduction of glades of overhead lines.

\section{Introduction}

One of the pressing issues for the power industry-cleaning of the walkways in the protected zones of overhead lines. Analysis of incidents and accidents at network facilities in recent years shows that the fall of trees and touching the branches of wires are the main causes of about a third of all power line outages. According to the security requirements of the alignment of overhead lines should periodically clean up on wood-handicraft vegetation.

The fall of trees on the power line, broken wires, and, therefore, the termination of electricity supply to consumers - the main reason for emergency situations in the power grid complex, as a significant part of the power lines pass through forests. In addition, most of the air lines were built in the 60-70-ies of the twentieth century-the trees during the operation of power lines have grown strongly. Today, the width of the cutting of air lines due to the increase in the height of the trees does not meet the existing standards.

For example, in connection with the established dry weather and abnormally high air temperature in several Russia regions in the summer of 2010, an emergency regime was introduced in the Republics of Mari El and Mordovia, as well as in the Vladimir, Voronezh, Moscow, Nizhny Novgorod and Ryazan regions. The Federal Grid Company introduced additional measures to improve the level of fire safety in the territories where the emergency regime was declared in the areas of responsibility of the MEA of the centre and the MEA of the Volga. During the period of abnormally high temperatures, many additional measures were taken to ensure the reliable operation of the UNEG, which allowed avoiding serious damage to the UNEG overhead line. Elements of supports, wires, insulators, fittings were in good condition. However, despite the measures taken, the equipment of several substations was damaged due to the impact of abnormally high temperatures. After forest fires on the routes of overhead lines, the company's employees carried out clearing of the tracks from the burned trees and checking the condition of the overhead line elements. All these actions helped to minimize the impact of fires on equipment of substations and transmission lines.

Now, in Russian Federation reduction of glades of overhead lines to the standard stateaccording to the decree of the Government of the Russian Federation No. 160 of 24.02.2009 clearing of territories from forest plantations near power lines on width shall be equal to the security zone of power lines. the conservation zone of the grid is the area along the overhead 
line in the form of a land plot and airspace on both sides from the outermost wires. At $0.4 \mathrm{kV}$ lines, this distance is 2 meters from the extreme wire, for $10 \mathrm{kV}-10$ meters, for $35 \mathrm{kV}-15$ meters, on $110 \mathrm{kV}$ lines-20 meters, $220 \mathrm{kV}-25$ meters.

Disconnection of even one power line with a voltage of $110 \mathrm{kV}$ can lead to the termination of power supply to several administrative districts of the country, at best for hours (if you just remove the fallen tree from the power lines wires), or even for a day (if there is a break in the wires or a drop in the power line supports). In the summer it will affect the operation of water supply facilities, electric transport, refrigerators, air conditioners, and in winter (as the tree was not removed during) can lead to the shutdown of boilers and freezing of heating systems.

Thus, clearing of glades in the areas of high-voltage lines annually is a priority direction of the repair campaign and one of the conditions for obtaining a passport of readiness of networks for winter. The emergency also occurs with strong winds and hurricanes (windfalls and windbreaks in forest plantations) as a result of falling trees on the wires and the breakage of the wires themselves or damage to the power transmission towers. For this reason, clearing of routes is one of the most important actions for increase of reliability of work of the main power lines. In addition, timely cleaning of trees and shrubs provides unhindered access to the facilities located on the highway.

In accordance with the approved program, the company is working on clearing and expanding the routes along the power lines. The measures are implemented in the framework of integrated preparation of the electric grid sector for the autumn-winter period. The relevance of the annual activities to clear the glades and expand the routes near the power lines is due to the need to ensure the safety of consumers and uninterrupted power supply. Bringing the glades in the regulatory state avoids the incidence of trees on the power line, thereby improving the reliability of electrical equipment.

The whole range of energy works is carried out exclusively in accordance with the current legislation of the Russian Federation, with the support and in cooperation with the forestry and environmental authorities, the Prosecutor's office, as well as representatives of the authorities. At the same time, it should be noted that in the implementation of the program for clearing roads and glades in some cases, PJSC FGC UES specialists are faced with a lack of understanding of the importance of the work carried out by the local population (owners, tenants, owners of sites with limited access to them).

The safety of the population is of paramount importance to PJSC FGC UES. This is to ensure uninterrupted power supply in compliance with all safety regulations and rules. From falling on the power line of a tree, located, for example, in a suburban area, can be left without light socially important objects-hospitals, schools, kindergartens-where power outages can be associated with a threat to life. This should be understood by everyone, including those who interfere with the work. Otherwise, they are liable for the full damage in case of breakage of transmission lines. Activity of PJSC FGC UES is based on the complex approach in the organization of all types of works, including on clearing of routes and glades.

It should be considered that in addition to the standard requirements in the form of optimization of time and cost, the environmental factor plays a special role in the clearing of routes. In addition, before carrying out work on clearing the glade, it is necessary to take into account the features of the landscape and the type of forest-business (suitable for subsequent processing) or non-business. This information allows you to split the object into several sections, each of which is formed by a complex team and the optimal composition of the mechanisms.

Maintenance of these sites may be difficult due to the availability of small-scale planted forests. This was especially evident during the winter period 2010-2011, 2016-2017. Heavy ice on wires and trees, resulting in a wire breakage and breakdown of many settlements. In the period of heavy snow precipitation at negative temperature trees under the weight of snow and ice broke, bent and broke the wires. This led to emergency situations on the power line. Elimination of accidents was difficult because of the low patency of equipment (big snow, broken trees, the presence of small forests). Only in the Moscow region, in order to ensure safety and stable operation, it is necessary to cut down about 8 thousand hectares of forest on the power lines. Statistics of shutdowns on the networks due to the fall of trees confirms the feasibility of the work: last year, their number decreased by almost 5 times compared to 2011.

In the framework of PJSC FGC UES's repair programme in 2017, repairs and maintenance of substation equipment and highvoltage lines were performed. Also, several unscheduled projects were scarried out in order to implement the priority measures for preparing the electric power engineering entities for the autumnwinter period 2017-2018. Actual expenses for repairs and target programmes for 2017 amounted to RUB 11,519 million.

Considering the importance of timely clearance of overhead lines, it was decided to switch to long-term (3 years) agreements for clearance of overhead lines in PJSC FGC UES.

Summing up and considering the importance of timely clearance of overhead lines, it was decided to switch to long-term (3 years) contracts for clearance of overhead lines in PJSC FGC UES.

Main advantage:

A. The conducted marketing analysis showed the presence of a competitive environment in the market.

B. With a multi-year contract, the contractor can plan its activities in advance and optimize the cost price for work guaranteed by the customer.

C. Problems with admission to work in the Sochi national Park do not depend on the duration of the contract with the contractor and can be solved by the customer outside the contract for the clearance of overhead routes from the VDK using easement tools. 
D. Through procurement procedures, it is possible to reduce the initial (maximum) price by $47 \%$ (from 59079.62 rubles/ha or 21.8 million rubles to 31293.12 thousand rubles/ha or 11.6 million rubles, including VAT).

Formation of the repair programme in 2017-2018, was carried out taking into account:

A. Measures aimed at ensuring the uninterrupted operation of the power grid complex in the conditions of the autumn-winter period (AWP), fire-dangerous, thunderstorm and flood periods, additional preventive measures that increase the security of electric grid facilities from the effects of natural phenomenon, as well as additional measures aimed at improving the reliability of the facilities power grid complex of PJSC FGC UES based on the results of the readiness check for the AWP, agreed with JSC SO UES;

B. Measures aimed at fulfilling the requirements of Rostechnadzor, elimination of comments revealed by external and internal supervisory control bodies (Ministry of Energy of Russia with the participation of JSC Technical Inspection of the Unified Energy System, branch PJSC Rosseti-the Center for Technical Supervision), affecting the provision of reliable power supply to consumers, as well as obtaining passports of readiness for the passing the AWP 2017-2018.

C. Measures for the preparation and organization of operation of power grid facilities of PJSC FGC UES for the holding of the Eastern Economic Forum.

D. Carrying out 2017 repair campaign was influenced by the following factors:

E. The need to complete the main works affecting the obtaining of passports of readiness for the AWP until 01.10.2018.

F. Liquidation of consequences of emergency outages in the power grid complex, including elimination of the consequences of «icy rain» on OTL 220-500kV MPS Volga.

G. Organization of inspections and thermal imaging control of overhead lines and equipment of the substation in the area of responsibility of the branch of PJSC FGC UES - MPS of the South, affecting the reliable power supply of the Crimean Peninsula.
Conducting timely repairs, as well as a reliable assessment of the technical condition of the main equipment by technical specialists of enterprises operating UNEG facilities, is the guarantee of reliable and uninterrupted power supply to consumers. In accordance with the Long-Term Development Programme of PJSC FGC UES in 2017, the full load of its own repair personnel is provided, taking into account the balance and uniformity of its employment during the year, including by performing additional works outside the repair campaign for investment and unregulated activities, which together led to an increase in the coefficient of efficiency of loading 6 of repair personnel by $1.3 \%$ in the reporting period compared to 2016 (from $112.8 \%$ in 2016 to $114.1 \%$ in 2017 ) with unconditional compliance with requirements of the Russian Federation Labor Code. At the same time, the main factor in increasing the load of own repair personnel in 2017 is an increase in the amount of maintenance and repair (TMR) work carried out in an economic way by $6.5 \%$ or 0.5 billion rubles (from 7.5 billion rubles in 2016 to 8.0 billion rubles in 2017). This also allowed fulfilling the tasks of optimizing operational costs and increasing the efficiency of using available human resources [1,2].

A. Reduced the standards of time and prices for clearing the routes of OTL from tree and shrubby vegetation as a result of changes in the technology of the use of chainsaws and brush cutters.

B. Standards of time and prices have been developed for mechanized clearing the routes of OTL from tree and shrubby vegetation using mulchers.

C. The differentiation of technology and the conditions of production of works on OTL.

Developed operational costs of DUOC for work on OTL, the use of which allows us to avoid duplication of preparatory-final general operations when combining works.

\section{References}

1. Decree of the Government of the Russian Federation No. 160 of 24.02.2009

2. Long-Term Development Programme of PJSC FGC UES. 